\title{
A ESCOLA PÚBLICA E O ACOLHIMENTO AOS IMIGRANTES NA CIDADE DE SÃO PAULO: UMA EXPERIÊNCIA NA EDUCAÇÃO DE JOVENS E ADULTOS
}

\author{
PUBLIC SCHOOL AND ACCOMMODATION FOR IMMIGRANTS IN THE \\ CITY OF SAO PAULO: THE EXPERIENCE IN YOUTH AND ADULT \\ EDUCATION
}

\author{
Adriana de Carvalho Alves Braga \\ Doutora em Educação, Arte e História da Cultura \\ Universidade Presbiteriana Mackenzie - UPM \\ São Paulo, SP - Brasil \\ andritsena@hotmail.com
}

\begin{abstract}
Resumo: $\mathrm{O}$ artigo trata do acolhimento, da socialização e do relacionamento de estudantes imigrantes na escola pública da cidade de São Paulo, além de discutir os conceitos de identidade, de papéis sociais, de etnicidade, de estereótipos e de xenofobia. Por meio da análise da experiência docente, mediando a aprendizagem de mulheres bolivianas na Educação de Jovens e Adultos em aulas de História, objetivamos contribuir com a compreensão da importância do acesso à educação para a efetivação do projeto migratório, da mobilidade social e do aprendizado da Língua Portuguesa. A descrição de algumas situações presenciadas pela autora revela situações de conflito - relacionadas ao mundo do trabalho e à própria construção e redefinição identitária nesse percurso migratório - que se manifestaram no ambiente da sala de aula e oportunizaram a reflexão sobre algumas nuances sobre o fenômeno migratório contemporâneo.
\end{abstract}

Palavras-chave: educação para imigrantes; interculturalidade; identidade; imigrantes bolivianas em São Paulo.

Abstract: This paper is about the reception, socialization, and the relations of immigrant students' in a public school in São Paulo city, besides discuss the identity concepts, social roles, ethnicity, stereotypes, and xenophobia. Through the analysis of teacher's mediation experience of Bolivian women learning in youth and adult education in history classes. We seek to contribute with the comprehension about the importance of the education access to the migratory project, social mobility, and Portuguese learning. The description of some situations experienced by the author, reveals conflicts regarding work and to the own construction and redefinition of the identities in this migratory process, which arise in the classroom environment and help the reflection about some shades in the contemporary migratory process.

Keywords: immigrant education; interculturality; identity; bolivian immigrants' women in São Paulo.

\section{Para citar - ABNT NBR 6023:2018}

BRAGA, Adriana de Carvalho Alves. A escola pública e o acolhimento aos imigrantes na cidade de São Paulo: uma experiência na educação de jovens e adultos. Cadernos de Pós-graduação, São Paulo, v. 20, n. 1, p. 77-90, jan./jun. 2021. Disponível em: https://doi.org/10.5585/cpg.v20n1.19284. 
Introdução

A imigração ocasiona uma profusão de sentimentos e de redefinições identitárias não apenas para os sujeitos imigrantes, mas também para a sociedade acolhedora e, tendo em vista que a formação da identidade é uma construção processual e contínua, os repertórios culturais vão adquirindo novas significações. Nesse contexto, pressupõe-se que a instituição escolar seja o espaço do encontro das múltiplas culturas e, por essa razão, torna-se estimulante refletir sobre o fenômeno da imigração a partir da vivência escolar e, em especial, como se redefinem as identidades e são negociados os papéis sociais a partir do acesso à educação formal.

No intuito de compreender como são mobilizadas as identidades na contemporaneidade, recorremos a Stuart Hall que, ao elencar três concepções de identidade, argumenta que, no sujeito pós-moderno, essa constituição identitária se caracteriza como um processo provisório, variável e problemático (HALL, 2015).

Nesse sentido, entendemos que o senso de pertencimento à comunidade é um mecanismo de defesa contra a solidão e o vazio ocasionados pelo deslocamento e, para Silva (2005), nesse processo migratório, a cultura não se perde nem se funde, mas se concentra em alguns traços língua, festas - que cumprem o papel de diferenciar culturalmente os sujeitos em situações específicas, bem como o de demarcar essas diferenças quando necessário. Logo, é relevante compreender como se constrói essa trajetória de sujeito migrante sob o ponto de vista do acesso à educação e das relações sociais desenvolvidas na escola.

Refletindo sobre os resultados dos processos migratórios e sobre a cultura, fruto de pesquisa realizada junto às comunidades de imigrantes bolivianos, Silva pondera que "ao entrar em contato com outra cultura, uma nova forma de ver o mundo, o imigrante terá que reelaborar a sua própria visão, incorporando novos valores e tradições que irão nortear a sua vida no local de destino" (SILVA, 2005, p. 45) e é justamente nesse processo de reelaboração identitária que se insere a escola, pois o contexto escolar é um espaço, via de regra, onde se impõe uma certa perspectiva monocultural, e é onde as negociações ocorrem.

Nessa perspectiva, apresentaremos, neste texto, o resultado de uma análise, sob a ótica docente, de como se desenvolvem as relações entre estudantes imigrantes bolivianas no cotidiano da sala de aula, vivenciado em uma escola pública, especificamente na Educação de Jovens e Adultos da Rede Municipal de Ensino de São Paulo. 


\section{Educação para Imigrantes: bases conceituais}

A articulação entre a educação e o fenômeno dos fluxos migratórios contemporâneos pode ser desvelada por meio do estudo de alguns conceitos, tais como: a globalização, as identidades, as políticas de acolhimento, entre outros.

Assim, considerando-se que uma das características da globalização, na contemporaneidade, é a de cumprir a função de remodelar as relações econômicas e sociais, podemos compreender o deslocamento no século XXI como um dos elementos que auxiliam na constituição desses fluxos.

Sob essa perspectiva, tendo em vista que a reestruturação do capitalismo marca a reconfiguração desses fluxos, o Brasil revela-se como destino migratório, especialmente em virtude da permeabilidade das fronteiras, o que contribui para o deslocamento fronteiriço, levando-se em conta a seguinte afirmação:

No caso desses movimentos migratórios torna-se ainda mais evidente que a importância do fenômeno reside nas novas situações presentes nos processos migratórios intrarregionais, já que a enorme diversidade e a potencialidade de espaços da migração na América Latina contribuem para uma menor concentração nos volumes de migrantes. (BAENNINGER; BÓGUS, 2018, p. 114)

Esses estudantes que chegam às escolas públicas da cidade de São Paulo têm origem especialmente nos países do cone sul, contudo, a partir de fluxos mais recentes, avolumam-se as presenças de caribenhos e de africanos. Dessa forma, diante dessa multiplicidade de culturas de origem, torna-se premente que o professor esteja sensível às transformações sociais, reorientando suas práticas, suas concepções e suas metodologias. Nesse sentido, os movimentos em defesa da democratização da educação têm promovido críticas ao modelo monocultural e sugerido um giro, em que se considere a visibilidade dos sujeitos envolvidos no processo ensino-aprendizagem quanto a seus direitos educativos.

Pensando na atuação docente, são relevantes as contribuições de Shulman (2014) a respeito das bases de conhecimento que são mobilizadas no oficio de ensinar e, ao tratar dos aspectos do raciocínio pedagógico, o autor afirma que é esperado que professores "entendam o que ensinam e, quando possível, entendam-no de muitas maneiras. Devem entender como uma ideia dada relaciona-se com outras ideias dentro do mesmo assunto e também com ideias de outros assuntos" (SHULMAN, 2014, p. 217).

Dessa maneira, as reflexões sobre as bases de conhecimento não tergiversam dos propósitos educativos, nem da compreensão sobre o conteúdo a ser ensinado, e é na articulação entre a especificidade do conteúdo e o saber pedagógico mais amplo que esses aspectos vão se revelando. 
[...] a chave para distinguir a base de conhecimento para o ensino está na interseção entre conteúdo e pedagogia, na capacidade do professor para transformar o conhecimento de conteúdo que possui em formas que são pedagogicamente poderosas e, mesmo assim, adaptáveis às variações em habilidade e histórico apresentadas pelos alunos. (SHULMAN, 2014, p. 217)

Em articulação com o tema da presença do imigrante, podemos inferir que as bases de conhecimento necessárias são aquelas que implicam uma apropriação dos saberes e das intenções do ensino em estreito diálogo com as demandas colocadas pelo que é "tecido junto", conforme apontou Morin (2009). Assim, esses saberes podem contribuir com a percepção da articulação entre os objetos de conhecimento como elementos porosos a outras áreas, não apenas à disciplina na qual é especialista, além de considerar as especificidades do grupo discente e, tratando-se de estudantes imigrantes, são notáveis as possibilidades de intersecção entre os conteúdos de ensino.

Dessa forma, a presença dos imigrantes na escola propõe o debate sobre a inadequação de uma proposta de ensino monocultural que, pensada de forma homogênea, concretiza-se enquanto ação pedagógica voltada a um público multicultural. Ignorar e tornar invisíveis as diferenças culturais no processo educativo acarretam prejuízos para os aprendizes e o contrário disso seria justamente a compreensão da dinâmica escolar como espaço de produção de problematizações da prática social. Portanto, faz-se necessário um giro conceitual de modo que “[...] a educação passa a ser entendida como uma relação entre os sujeitos, vistos não apenas como indivíduos, mas como constituídos e constituintes de seus respectivos contextos socioculturais" (FLEURI, 2009, p. 108). É nessa relação de mediação que o professor pode atuar, promovendo situações educativas que garantam tanto a visibilidade dos sujeitos quanto a valorização de suas trajetórias pessoais, contribuindo, assim, com mais um passo em sua formação.

A discussão sobre repertórios culturais e a construção dos simbolismos decorrentes do processo de migração foi desenvolvida em profundidade por Seixas (2016) e, para o autor, tratar de repertórios culturais é compreender que os contextos de trocas culturais não se restringem a uma compreensão impermeável de identidade, pois, para ele, estes dizem respeito a narrativas tanto individuais quanto de grupos. Para tratar das especificidades das trocas culturais entre o sujeito e o meio no qual se insere, o autor argumenta que

A partir do repertório cultural que ele tem e que compartilha com seu grupo, cada indivíduo constrói narrativas por meio das quais tenta reorganizar o caos da vida real e transformá-la num cosmos que faça sentido para ele, ser humano, e também para o grupo social em que se insere (SEIXAS, 2016, p. 21) 
Não podemos ignorar que, na complexidade das trocas culturais, inserem-se também elementos da reprodução da vida material que influenciam os sujeitos quanto às suas escolhas societárias. Nesse sentido, a exploração do trabalho é uma categoria interessante para compreender as dinâmicas sociais estabelecidas, especialmente porque se trata de um elemento que macula os laços de solidariedade e impele alguns sujeitos a buscar apoio em outros grupos, diversos daquele em que eles compartilham os repertórios culturais. No texto, descreveremos o modo como essa condicionante manifestou-se nas dinâmicas sociais construídas em sala de aula.

Tão importante quanto compreender que as identidades se redefinem na migração, e que essa constituição é um processo provisório, é analisar como essas identidades mobilizam-se no que diz respeito ao exercício dos papéis desempenhados pelos sujeitos na experiência social. Tratando de diferenciar os conceitos de identidade e de papel social, Castells sugere que "em termos mais genéricos, pode-se dizer que identidades organizam significados, enquanto papéis sociais organizam funções” (CASTELLS, 2018, p. 55) e, para a análise do fenômeno que nos propomos investigar, essa distinção é oportuna.

Contribuindo para a compreensão dos papéis sociais, Castells (2018) afirma que estes são definidos a partir de negociações entre os sujeitos e as instituições e organizações da sociedade. Já as identidades são construídas em contextos marcados por relações de poder, e o autor elenca três formas e origens da construção das identidades: a identidade legitimadora seria introduzida pelas instituições socialmente dominantes; a identidade de resistência, promovida pelos atores socialmente estigmatizados pelas lógicas de dominação e; as identidades de projeto, que propõe a redefinição e transformação da estrutura social.

A partir dessas considerações, poderíamos inferir que os estudantes pertencentes às comunidades imigrantes podem ser entendidos enquanto sujeitos que constroem suas identidades a partir da resistência, além de conviverem com o constante assédio para se ajustarem, para assimilarem e para incorporarem o que Castells definiu como "identidade legitimadora", a qual busca silenciar a diversidade. E, nesse aspecto, as percepções sobre a sociedade acolhedora tensionam essa definição identitária a partir dos estereótipos que recaem sobre as comunidades imigrantes.

Esses estereótipos estão estreitamente relacionados ao panorama dos fluxos migratórios contemporâneos na cidade de São Paulo, marcados por um expressivo adensamento da migração de andinos e, mais recentemente, de caribenhos e africanos. A esse respeito, Silva sugere que pode ser observada uma alteração significativa no acolhimento desses imigrantes, sendo que se destaca "a forma como a sociedade brasileira passou a lidar com as diferenças étnico-culturais, já que a imigração se apresentava como uma realidade pretérita e resolvida no imaginário nacional” (2008, 
p. 9) ou seja, lidar com esse novo contexto migratório exige que sejam revistos alguns preconceitos estruturais da sociedade brasileira.

A expressão "realidade pretérita e resolvida no imaginário nacional", utilizada por Silva (2008), é uma das questões primordiais que se colocam na sociedade brasileira contemporânea quando o tema é imigração, e, por essa razão, é importante resgatar a constituição desse imaginário e quais elementos históricos o produziram. Quanto aos confrontos entre a imigração e a identidade nacional, Seyferth(2000) ${ }^{1}$ discute os elementos da imigração europeia no Brasil e assinala que, aos nacionalistas, incomodava a concentração e o isolamento das colônias de imigrantes no sul do país, sendo este um fator que poderia gerar um desequilíbrio regional.

Esse incômodo decorria do projeto de branqueamento a partir das teorizações racistas que almejavam valer-se do grande contingente de imigrantes brancos europeus para alterar o quadro racial brasileiro, dirimindo os traços negros e indígenas da população. Compreendidos a partir da tarefa de branquear, objetivava-se que esses imigrantes "desejáveis" se incorporassem a esse projeto político, assimilando a cultura brasileira e abrindo mão de suas identidades étnicas.

Portanto, o que diferencia o incômodo de outrora ao que se observa na sociedade atual é justamente o critério raça/cor, pois, no contexto migratório da cidade de São Paulo, no século XXI, são numerosas as comunidades de bolivianos, de peruanos e de paraguaios, além de imigrantes oriundos de diversas regiões do continente africano. São contra esses grupos que se dirigem as manifestações de xenofobia e de outras formas de violência, além do questionamento e do cerceamento de direitos sociais.

De acordo com Silva (2008), as comunidades imigrantes latinoamericanas são caracterizadas a partir do histórico migratório para o Brasil, das relações de trabalho, das manifestações de produção cultural, bem como dos elementos de inserção na cidade. O autor explica que essa escolha se deve a um conjunto de fatores que colocam os latinoamericanos em condições desiguais de inserção na sociedade, e destaca os problemas jurídicos da falta de documentos, além da exploração da mão-de- obra e dos preconceitos construídos pela sociedade local como principais barreiras de acolhimento.

Esses apontamentos auxiliam-nos a identificar a origem migratória como fator de entrave no processo de acolhimento das comunidades imigrantes latinoamericanas, todavia existem outras condicionantes que interferem nesse processo. Como já mencionamos, o mundo do trabalho emerge como uma importante categoria de interpretação dos fluxos contemporâneos. A esse respeito, Silva (2006) elabora uma interessante análise sobre a relação entre imigração e trabalho e, em

\footnotetext{
1 Sobre a temporalidade abordada, a autora salienta que o período histórico considerado "corresponde ao de maior fluxo imigratório (aproximadamente 1880-1930)" (SEYFERT, 2000, p. 82)
} 
texto dedicado à descrição das estratégias adotadas pela comunidade boliviana para alcançar a mobilidade econômica por meio do trabalho nas oficinas de costura, relata as trajetórias usualmente percorridas por esses imigrantes.

Dentre as aventadas estratégias de mobilidade está o desejo de aquisição da própria oficina para que, na condição de autônomos, possam empreender negócios, angariando trabalhadores entre indivíduos da própria família e entre compatriotas. Nesse contexto, o oficio da costura é também a oportunidade de trabalho que encontram os jovens e adultos bolivianos quando migram para o Brasil e, a esse respeito, o autor destaca que eles alentam o desejo de estudarem e de se qualificarem para exercerem outras profissões, no entanto a extenuante rotina de trabalho não permite conciliar os horários de estudo.

Em relação ao reconhecimento social, Silva (2006) aponta que este é mais difícil que a mobilidade econômica, uma vez que sobre os bolivianos recaem estereótipos negativos. Acerca dessa imagem negativa o autor elucida que:

Esses são associados com frequência ao trabalho escravo e ao tráfico de mão de-obra para as oficinas de costura. Além dessa identificação negativa e que, às vezes, assume um caráter acusativo, eles têm que lidar com outros preconceitos decorrentes do desconhecimento de grande parte dos brasileiros de suas raízes étnicas e culturais. Para esses, eles são vistos como pessoas descendentes de "índios", "pobres" e de "pouca cultura". (SILVA, 2006, p. 166).

Essa dificuldade em alcançar um reconhecimento social favorável também é partilhada por outras comunidades latinas, pois atrelada a essa dificuldade está a origem étnica. Em outro texto, ao referir-se aos imigrantes bolivianos, peruanos e paraguaios, o autor identifica a discriminação racial social como elemento que pesa sobre eles, uma vez que peruanos e bolivianos, sendo "oriundos do contexto andino, são portadores de fenótipos semelhantes, em razão de raízes étnicas quéchua e aimará compartilhadas por ambos. Já no caso do último grupo, a etnia predominante é a Guarani”. (SILVA, 2008, p. 37).

Como a história brasileira foi construída com o racismo sendo um dos eixos estruturantes, a origem étnica desses sujeitos converte-se em elemento de diferenciação, a partir de uma hierarquia social que os coloca como inferiores, sendo esses imigrantes reduzidos ao conceito que se faz sobre os "índios" no Brasil, fator que intensifica a discriminação social ao se articular a xenofobia com o racismo.

Algumas pesquisas relacionadas ao campo da imigração têm se dedicado a investigar como os fluxos têm ocasionado a emergência de novos fenômenos sociais, reafirmando ou rompendo paradigmas sociais. Lucena (2013) contribui para essa discussão ao apontar a interface entre a identidade étnica, o deslocamento e a cidadania, já que, para a pesquisadora 
Os efeitos sócio-culturais dos atuais processos de internacionalização provocam uma redefinição e reformulação do conceito de cidadania. Os novos deslocamentos de grupos humanos por meio de novas identidades e de novas propostas de vida estimuladas pelo contexto atual global ampliam as trocas culturais, e ao mesmo tempo, ampliam os conflitos baseados na interculturalidade. O conceito de cidadania não deve permanecer baseado em concepções uniculturais e uniétnicas, urge pensar hoje em uma configuração ao conceito e aceitá-lo dentro de re-significações a partir das relações interculturais e interétnicas. (LUCENA, 2013, p. 11).

O que a autora denomina "conflito intercultural" é outro conceito importante para esta análise, pois esse tal conflito emerge, de maneira explícita, em situações em que a sociedade acolhedora se defronta com a necessidade de entender o outro em sua identidade cultural e com ele estabelecer suas relações. Ao propor a classificação do outro - o imigrante, o latinoamericano, o indígena -, o sujeito está mobilizando um referencial simbólico, baseado nas representações por ele construídas.

Temas como etnicidade, cidadania e direitos sociais, identidade e globalização são relevantes e compõem o escopo desse processo de acolhimento. Por essa razão, torna-se mister que a pesquisa relacionada a esses fluxos migratórios aponte para o desvelamento das construções simbólicas que se desencadeiam a partir dessa presença imigrante na sociedade.

\section{Trajetórias pessoais das estudantes imigrantes: suas origens, percepções e sonhos}

No exercício do trabalho docente, pudemos vivenciar situações que motivaram a considerar a complexidade da identificação tanto étnica quanto sociocultural dos imigrantes e, no ano de 2014, lecionando a disciplina História em uma escola localizada no bairro da Casa Verde ${ }^{2}$, ministrada para uma turma na Educação de Jovens e Adultos, no período noturno, presenciamos situações de choque, de resistência e de acolhimento de estudantes.

Nessa escola da Casa Verde, foi possível conviver cotidianamente, no período de um ano, com três alunas bolivianas adultas, que tinham idades e perfis muito diferentes, o que nos possibilitou realizar uma imersão cotidiana nesse tema que estimula tanto debate. Assim, iniciamos o resgate dessa memória com a estudante Carmen. Ela tinha cerca de 40 anos e havia migrado para o Brasil há mais de 15 anos, trabalhava em uma oficina de costura que era gerenciada pelo próprio marido e vivia com sua família em uma moradia próxima à escola.

Carmen tinha fenótipo indígena, não frequentou escola na Bolívia e dizia que cresceu no campo e, por essa razão, não foi alfabetizada em seu país. Aprendeu a ler e a escrever na escola da Casa Verde, onde se matriculou na etapa de alfabetização ${ }^{3}$. Após algumas retenções - a pedido da

\footnotetext{
${ }^{2}$ Nomes fictícios. O nome da escola e das alunas foi omitido, para preservar a identidade delas.

${ }^{3}$ A Educação de Jovens e Adultos da Rede Municipal de Ensino de São Paulo compreende quatro Etapas: Etapa Alfabetização (2 semestres), Etapa Básica (2 semestres), Etapa Complementar ( 2 semestres) e Etapa Final (2 semestres). Ao término da Etapa Final, o estudante está apto para prosseguir os estudos no ensino Médio.
} 
própria aluna para intensificar especialmente o aprendizado de Língua Portuguesa -, estava concluindo a etapa final e dizia ser auxiliada por uma das filhas que estudava na mesma escola, no período diurno, e tinha melhor compreensão do português.

Era notória a dificuldade de compreensão dos conceitos e a estudante pouco participava das discussões da aula, apesar de muitas explicações individualizadas serem realizadas em castelhano. Essa dificuldade de compreensão da língua e dos conceitos influenciava diretamente o desempenho escolar de Carmen, que muitas vezes não alcançava o rendimento que almejava. Devido à rotina extenuante de trabalho, a estudante muitas vezes dormia sobre a carteira e, em virtude de ser muito reservada socialmente, em nossas conversas, não foi possível dialogar sobre suas percepções sobre a escola e/ou sua identificação étnica.

A segunda aluna, Viviana, na faixa etária dos 30 anos, havia deixado os quatro filhos sob os cuidados da mãe, em Santa Cruz de La Sierra, e migrou sozinha para São Paulo. Inicialmente, trabalhou em oficinas de costura na região - inclusive na oficina do marido de Carmen, fato que, de acordo com informações obtidas por meio do diálogo com outros professores, já havia desencadeado alguns conflitos na sala de aula.

Viviana deixou as oficinas de costura e conseguiu trabalho como repositora em um hipermercado da região e, no decorrer do ano letivo, seus filhos foram viver com ela, sendo matriculados na mesma escola, em período diurno, o que a deixou muito feliz, pois assim concretizou seu projeto migratório: reunir sua família em São Paulo. A estudante também empreendia muito esforço no aprendizado, alcançando bom desempenho e boas notas em todas as disciplinas e, assim, almejava concluir o Ensino Médio para obter reconhecimento e mobilidade, especialmente em seu local de trabalho.

Uma situação muito interessante ocorreu em uma de nossas aulas de História do Brasil, na qual o conteúdo ensinado era a contribuição dos povos indígenas e suas resistências, quando Viviana relatou-nos que seu pai era indígena e que falava a língua Guarani. Obviamente essa informação despertou curiosidade na turma, entretanto, quando questionada sobre sua identificação étnica, a estudante afirmou que seu pai era indígena, ela não, era "boliviana". Após enfatizar essa identificação, a aluna argumentou que na Bolívia os indígenas eram tratados como inferiores, e que ela não queria sofrer essa discriminação.

Em nossos diálogos, Viviana dizia que, assim que chegou ao Brasil, converteu-se ao protestantismo e passou a frequentar uma igreja evangélica, alegando que não gostava de participar dos espaços societários de seus compatriotas, sob o argumento de que havia muita violência. No ambiente escolar, buscava consolidar laços de amizades predominantemente com mulheres brasileiras, 
o que podia ser observado no momento dos intervalos das aulas e durante a realização de trabalhos em grupo na sala de aula.

$\mathrm{Na}$ mesma turma estava matriculada Patrícia, jovem de 19 anos, que iniciou seus estudos na Bolívia e estava prestes a concluir o Ensino Fundamental depois de algum tempo longe da escola e, dentre as três estudantes, ela era a que tinha a fluência na Língua Portuguesa mais desenvolvida. Trabalhava como balconista em uma loja de aviamentos na região e tinha pretensões de prosseguir os estudos e chegar à universidade.

Em uma de nossas aulas, cujo conteúdo relacionava-se aos alimentos e suas origens, salientamos as propriedades nutritivas da quínua e Patrícia declarou que "não aguentava nem ouvir falar" desse alimento. De acordo com ela, sua mãe preparava quinua todos os dias, nas mais variadas refeições: "era caldo de quínua no café da manhã, sopa de quínua com batata, salada de quínua...", enfim, a simples menção a esse alimento já lhe causava repulsa. Cabe ressaltar que, no debate em sala de aula, os estudantes brasileiros já tinham ouvido falar desse alimento, mas afirmaram nunca o haver experimentado, logo esperava-se que as estudantes bolivianas relatassem seus hábitos em relação a ele.

\section{A paisagem humana da escola da Casa Verde}

$\mathrm{Na}$ escola havia outros estudantes imigrantes, todos bolivianos, e uma das estratégias que a escola utilizava para proporcionar o estreitamento dos laços de amizade eram as festas, realizadas ao final de cada bimestre. Nessas ocasiões, os estudantes eram estimulados a levar alimentos para compartilhar com colegas e professores, sendo comum os bolivianos levarem pratos típicos de seu país, como salteñas, chicharrón e doces, o que propiciava, além do resgate de uma memória gustativa, o compartilhamento e a apropriação de uma cultura diferente por parte dos brasileiros, tanto dos estudantes quanto dos educadores.

Como estratégia de acolhimento, destacava-se também o acompanhamento mais individualizado, sendo parte da rotina a escola telefonar para a casa dos estudantes quando estes deixavam de ir à escola ou para incentivá-los a participar da formatura ou de outros eventos da rotina escolar. Nessas ocasiões, quando se tratava dos alunos bolivianos, o diálogo era realizado em castelhano, o que nos permitiu contribuir com esses momentos em diversas ocasiões devido ao domínio do idioma. Essas estratégias adotadas pela instituição de ensino para diminuir os níveis de absenteísmo e de evasão escolar evidenciam a intenção da escola de zelar pela permanência e de propiciar um

\footnotetext{
${ }^{4}$ Sobre a quínua, Brito (2016, p. 83) informa que "conhecida também como o trigo dos incas, o grão produz uma semente pequena, comestível, rica em proteínas, vitaminas e minerais. Os Incas chamavam de "chisiya mama”, o que significa em quéchua (língua nativa indígena) "mãe de todos os grãos". BRITO, Vitor Skif. Quinoa da gênese ao século XXI: 500 anos de dormência para uma nova perspectiva na alimentação. Contextos da Alimentação - Revista de Comportamento, Cultura e Sociedade, vol. 5 nº1, dez. de 2016. pp. 81-98.
} 
espaço acolhedor para esses estudantes, o que invariavelmente constitui um estímulo à persecução de seus sonhos e de projetos de vida.

As experiências propiciadas pelo contato com esses estudantes possibilitaram desencadear profícuas reflexões sobre a articulação entre a migração, a sociabilidade, a identificação étnica e a importância da escola para o acolhimento de imigrantes. Pode-se, assim, seguramente, afirmar que as situações descritas não dão conta de abarcar toda a complexidade passível de ser observada na construção das relações entre os estudantes imigrantes e a escola, uma vez que o ambiente que descrevemos estava circunscrito à Educação de Jovens e Adultos, caracterizada especialmente pelo encontro de diferentes gerações, sendo uma modalidade de ensino em que se observa uma certa obstinação no empreendimento educativo, tanto da parte de estudantes brasileiros quanto dos imigrantes, que optam por esses cursos para alcançar a conclusão dos estudos.

Outro diferencial da Educação de Jovens e Adultos é a composição das turmas que, via de regra, são pouco numerosas, o que possibilita um diálogo mais estreito entre os estudantes e o(a) professor(a), de modo que podemos conhecer as trajetórias, muitas das dificuldades e quais projetos de vida são idealizados por esses estudantes. A oportunidade de conhecê-los muda a percepção sobre o papel da escola na concretização dos projetos de vida e mesmo os conflitos fornecem pistas sobre a construção dos laços de solidariedade. São esses caminhos percorridos, especialmente no que se refere à percepção desavisada de que todos os bolivianos fazem parte de uma grande comunidade coesa, que possibilitam avançar na compreensão da instituição escolar enquanto mobilizadora de identidades e promotora de direitos.

\section{$4 \mathrm{O}$ professor e a mediação das relações}

As discussões propostas a partir dos fluxos migratórios contemporâneos e da presença desses imigrantes na escola podem incidir favoravelmente sobre a problematização dos referenciais e as abordagens do currículo ensinado pelo professor, como também sobre a construção de relações dialógicas inspiradas numa perspectiva intercultural. Perpassando as áreas de conhecimento, por sua potencialidade interdisciplinar, a imigração pode favorecer o aprendizado sobre diversos conteúdos curriculares e, para tanto, é importante que o docente esteja atualizado e desenvolva ações que contribuam para a inclusão do tema em seus projetos de ensino. Na interface entre o currículo e o fenômeno social, a presença de estudantes imigrantes tem o potencial de enriquecer as abordagens de ensino por meio do relato das trajetórias pessoais e da pesquisa dos contextos de origem.

É na sala de aula que se desenvolvem as relações entre professor e estudante, no entanto tratar de um tema tão desafiante e complexo a partir de uma disciplina ou de uma área do conhecimento não nos propiciaria apreender o que foi tecido junto, conforme expressou Morin (2009) 
ao criticar a hiperespecialização do conhecimento. Portanto, as discussões sobre a identidade e o exercício de papéis sociais, as relações desenvolvidas na escola, no mundo do trabalho, além da investigação sobre os projetos migratórios, surgem no contexto de ensino para imigrantes e são problemáticas aglutinantes, o que requer aportes conceituais das mais diversas áreas do conhecimento.

Muitos dos relatos que expusemos sobre as estudantes bolivianas da escola da Casa Verde foram coletados no decorrer de situações didáticas que colocaram em diálogo distintas áreas do conhecimento. Essa experiência tornou-se possível, enquanto narrativa docente, porque foram planejados momentos em que a participação discente fosse estimulada, cabendo a mediação entre a história vivida e o currículo prescrito.

Para Viviana tornou-se importante definir e exercer um papel social que a inserisse na sociedade acolhedora, e sua trajetória como mulher e como mãe imigrante forneceu-nos pistas interessantes a respeito do processo de escolha de decisão sobre esse papel. Primeiramente, ela se aproximou de um grupo social - igreja - em que recebeu o alento para a solidão e para o vazio ocasionados pelo processo migratório, e se distanciou de seus compatriotas. A segunda ruptura foi com o mercado de trabalho, pois deixou as oficinas de costura e se empregou em um trabalho formal, ainda que com menor remuneração e pouco prestígio, o que demonstra que ela procurou se afastar do estigma que recai sobre a população boliviana em São Paulo.

A discussão da origem étnica como mecanismo de diferenciação e hierarquização social está presente no discurso de Viviana, quando a estudante expõe sua narrativa familiar e fala de seu pai, que identifica como Guarani. Das três estudantes bolivianas com quem convivemos naquele ano, ela era a que mais se expunha, e buscava afirmar-se nesse papel de mulher imigrante boliviana que rompia com os estereótipos vinculados à sua origem nacional. Em sua narrativa, é possível identificar que mediante a estereotipia e o preconceito, uma vez que sua escolha foi a de se afastar do estigma, e "ser boliviana" em detrimento de ser Guarani, sua opção pode ser entendida como uma das faces dessa recusa. Possivelmente ela já havia percebido que a discriminação dos indígenas não é um fenômeno social restrito à Bolívia e que, no Brasil, o ambiente também não era favorável para a afirmação de uma identidade étnica diversa.

Outra constatação que contribui para a compreensão da complexidade do tema é o fato de que, comumente, relaciona-se a materialidade de uma cultura aos hábitos alimentares, logo é confortável o pressuposto de que as comunidades andinas apreciam batatas, quínua e chicha. Desse modo, os relatos de Patrícia a esse respeito são enriquecedores, pois advertem para o desejo de apropriação de outros hábitos, dialogando com a cultura alimentar local. Para ela, estar em um 
outro país pressupõe a possibilidade de incorporação de novos hábitos alimentares, o que possibilitaria experimentar com profundidade essa experiência migratória.

Cabe observar que o fenômeno das migrações regionais tem colocado em xeque as percepções do senso comum da sociedade brasileira, uma vez que a proximidade física com esses sujeitos mobiliza não apenas os estereótipos e as generalizações, mas pode proporcionar a capacidade de problematização do próprio conceito de cidadania em relação à identidade étnica. Certamente os estudantes brasileiros da escola da Casa Verde confrontaram essas estereotipias e refletiram sobre os preconceitos ao conviver com pessoas de outras nacionalidades. Esse convívio com colegas imigrantes pode se traduzir em mudanças na percepção sobre o significado do convívio social com o diferente, potencializando a própria reflexão sobre o conceito de cidadania.

\section{Considerações finais}

Nesse texto, exploramos o tema da imigração a partir de situações vivenciadas, na condição de docente de História, em uma escola pública da cidade de São Paulo. Ressalta-se que a Educação de Jovens e Adultos, modalidade de ensino que garante os direitos educativos daqueles que não alcançaram a conclusão dos estudos na idade desejável, aponta como uma importante possibilidade de inclusão por parte das comunidades latinoamericanas, uma vez que não oferece apenas a certificação de finalização dos estudos mas também potencializa o aprendizado da Língua Portuguesa e a construção de relações sociais.

Com a inserção no ambiente escolar, o imigrante apropria-se dos códigos culturais daquele espaço, exercendo o papel de estudante ao mesmo tempo em que ressignifica sua identidade e realiza escolhas pertinentes à concretização de seu projeto migratório. Já no contexto da sala de aula são acionadas as memórias que possibilitam relacionar a conteúdo aprendido à história vivida, sendo este o momento em que emerge a possibilidade, por parte do professor, de produzir mediações pedagógicas significativas.

As trajetórias das mulheres imigrantes analisadas no texto revelam situações de conflito relacionadas ao mundo do trabalho e à própria construção e redefinição identitária nesse percurso migratório - que se manifestaram no ambiente da sala de aula e oportunizaram a reflexão sobre algumas categorias de investigação do fenômeno migratório. A opção por problematizar essas situações a partir de um referencial relacionado aos repertórios culturais permitiu que esses dilemas fossem considerados como subsídios para o estabelecimento de um diálogo intercultural.

Finalmente, é apontada a importância do professor na mediação das aprendizagens e das relações, considerando-se que a visibilidade dos sujeitos e a valorização de seus repertórios culturais são elementos primordiais que fundamentam a prática de uma educação intercultural e promotora 
de direitos. As demandas apresentadas pelo contexto contemporâneo devem ser entendidas, pelo professor, como bases para o seu trabalho, o que contribui para a superação de uma perspectiva homogênea e monocultural do ensino.

\section{Referências}

BAENINGER, Rosana; BÓGUS, Lucia. Emigração brasileira no Mercosul. In: A nova face da emigração internacional no Brasil. São Paulo: EDUC, 2018.

CASTELLS, Manuel. O poder da identidade: a era da informação. Volume II. $9^{a}$ edição Rio de Janeiro: Paz e Terra, 2018.

FLEURI, Reinaldo Matias. Educação Intercultural e a irrupção das diferenças. In: Globalização, interculturalidade e currículo na cena escolar. Campinas, SP: Editora Alínea, 2009.

HALL, Stuart. A identidade cultural na pós-modernidade. Rio de Janeiro: Lamparina, 2015.

LUCENA, Célia Toledo. Fluxos migratórios de latino-americanos: cidadania transnacional. Revista Ambivalências. Volume I, No 2. P. 05-28, jul-dez/2013.

MORIN, Edgar. A cabeça bem-feita: repensar a reforma, reformar o pensamento. $16^{\mathrm{a}}$ edição. Rio de Janeiro: Bertrand Brasil, 2009.

SEIXAS, Renato. Migraşão simbólica e dialética da identidade cultural no processo de migraşão. Cadernos Prolam/USP, v.15, n.29, p.14-37, jul/dez.2016.

SEYFERTH, Giralda. Identidade nacional, diferenças regionais, integração étnica e a questão imigratória no Brasil. In: Região e nação na América Latina. Brasília: Editora Universidade de Brasília; São Paulo: Imprensa Oficial do Estado, 2000.

SILVA, Sidney Antônio da. Bolivianos: a presença da cultura andina. Série Imigrantes no Brasil. São Paulo: Companhia Editora Nacional, 2005.

SILVA, Sidney Antônio da. Bolivianos em São Paulo: entre o sonho e a realidade. Estudos Avançados. v. 20, n. 57, 2006.

SILVA, Sidney Antônio da. Faces da Latinidade: Hispano-Americanos em São Paulo. Campinas: Núcleo de Estudos de População/Unicamp, 2008.

SHUMAN, Lee S. Conhecimento e ensino: fundamentos para a nova reforma. Cadernos CENPEC. São Paulo, v.4, n.2. p.196-229, dez. 2014. 